\title{
Contagem de células somáticas no leite de vacas suplementadas no pré-parto com selênio e vitamina $E$
}

\author{
Milk somatic cell count of selenium and vitamin E prepartum supplemented cows
}

\author{
Juliana Jorge Paschoal ${ }^{1}$ Marcus Antonio Zanetti ${ }^{2}$ José Aparecido Cunha $^{2}$
}

\section{RESUMO}

$O$ selênio e a vitamina $E$ são antioxidantes importantes na defesa de células e tecidos e atuam diretamente na manutenção da saúde do úbere, influenciando a contagem de células somáticas, indicador no leite da mastite. O presente trabalho teve como objetivo avaliar o efeito da suplementação do selênio e da vitamina E sobre a contagem de células somáticas no leite de vacas da raça holandesa, durante o período das águas. Oitenta animais foram distribuídos em quatro tratamentos: controle; suplementação com $2,5 \mathrm{mg} \mathrm{Se}$ dia $^{-1}$; suplementação com 1000 UI vit. E dia ${ }^{-1}$ e suplementação com 2,5mg Se +1000 UI vit. E dia ${ }^{-1}$. A suplementação foi iniciada 30 dias antes da provável data de parição, prolongando-se até o parto. Amostras do volumoso e do concentrado foram colhidas, quinzenalmente, para análise bromatológica completa e levantamento dos níveis de selênio. O sangue foi colhido antes do início da suplementação, no parto, 30 e 60 dias após o parto, para determinação dos níveis de Se no soro sangüíneo das vacas. O leite foi colhido semanalmente para determinação da contagem de células somáticas (CCS). O período de colheita iniciou-se logo após o período colostral, prolongando-se até a décima segunda semana de lactação. Um mês após a suplementação, as vacas que receberam selênio apresentaram níveis séricos superiores $(P<0,05)$ ao grupo controle. O selênio e a vitamina $E$ não afetaram $(P>0,05)$ a CCS nas doze primeiras semanas de lactação e não foi encontrado efeito de interação entre os dois elementos.

Palavras-chave: antioxidantes, mastite subclínica, pré-parto, qualidade do leite.

\section{ABSTRACT}

Selenium and vitamin $E$ are important antioxidants for cells and tissues protection acting directly as a support for the udder health. This experiment was aimed at

\begin{abstract}
evaluating the influence of prepartum selenium and vitamin $E$ supplementation on milk somatic cell counts of Holstein cows during summer period. Eighty animals were allocated into four treatments: control; supplementation with $2.5 \mathrm{mg} \mathrm{Se} \mathrm{day-1}^{-1}$; supplementation with 1000 UI vitamin $E$ day $^{-1}$ and supplementation with $2.5 \mathrm{mg}$ Se day ${ }^{-1}+1000$ UI vitamin $E$ day $^{-1}$. The supplementation started thirty days before the probable parturition date until parturition. Forage and concentrate samples were taken every fifteen days for chemical and selenium analyses. Blood samples were taken before starting supplementation, right after parturition, thirty and sixty days after it to determine the selenium serum levels. Milk samples were taken to determine somatic sell count (SCC). Selenium supplemented cows had higher serum selenium concentration compared with control group $(P<0.05)$. The selenium and vitamin $E$ did not decrease $(P>0.05)$ SCC up to $12^{\text {th }}$ week of lactation.
\end{abstract}

Key words: antioxidants, milk quality, prepartum, subclinical mastitis.

\section{INTRODUÇÃO}

Os efeitos favoráveis do selênio (Se) e da vitamina $\mathrm{E}$ (vit. E) nos mecanismos de defesa da glândula mamária vêm sendo estudados nos últimos anos, porém existem poucos trabalhos desenvolvidos no Brasil. A vit. E é o mais importante antioxidante lipossolúvel. Está inserida nas membranas lipídicas e protege-as contra o ataque de radicais superóxido (COMBS \& COMBS, 1986). O Se é um micronutriente essencial presente nos tecidos do corpo e é parte integrante da enzima glutationa peroxidase que atua

${ }^{1}$ Universidade de São Paulo (USP), Faculdade de Zootecnia e Engenharia de Alimentos (FZEA), Programa de Pós-graduação em Zootecnia, Pirassununga, SP, Brasil. Avenida Apolônio Salles 361, 38020-430, Uberaba, MG, Brasil. E-mail: julianajp@yahoo.com.br. Autor para correspondência.

${ }^{2}$ USP, FZEA, Departamento de Zootecnia, Avenida Duque de Caxias Norte, 225, 13630000, Pirassununga, SP, Brasil. 
no citosol celular convertendo peróxido de hidrogênio (composto tóxico) em $\mathrm{H}_{2} \mathrm{O}+\mathrm{O}_{2}$ (COMBS e COMBS, 1986). Os antioxidantes têm a função de impedir que haja acúmulo de espécies reativas de oxigênio no meio celular, minimizando danos comprometedores sobre as células de defesa da glândula mamária (PAES et al., 2003).

Sabe-se que a mastite é a principal doença infecto-contagiosa em animais destinados à produção leiteira (LANGONI, 2000). A incidência de mastite subclínica é alta no Brasil, acometendo até $71 \%$ das vacas em rebanhos de Minas Gerais e São Paulo (COSTA et al, 1995; COSTA et al., 1999).

O primeiro estudo sobre o efeito do Se e da vit. E na incidência de mastite clínica foi realizado por SMITH et al. (1984). Os autores verificaram diminuição de $37 \%$ na incidência de mastite clínica em vacas que receberam suplementação de 740 UI de vitamina E por dia, durante o período seco.

A suplementação com Se em níveis crescentes (ideal até $5 \mathrm{mg} \mathrm{dia}^{-1}$ ) foi investigada por MAUS et al. (1980); os autores constataram aumento na concentração de Se no sangue e diminuição na incidência de mastite clínica e na contagem de células somáticas (CCS) no leite. Do mesmo modo, a suplementação com vit. E em níveis crescentes aumentou a concentração de alfa tocoferol no sangue (mais significativo em vacas secas) e diminuiu a incidência de mastite clínica (WEISS et al., 1990).

Em trabalho utilizando 2.000 UI de vit. E dia $^{-1}$ no pré-parto, WEISS et al. (1997) diminuíram a incidência de mastite clínica de 25\% para 2,6\%. VALLE (2000) suplementou vacas no pré e pós-parto com níveis de vitamina E variando de 1.000 a 3.000 UI dia-1 e constatou maior incidência de mastite clínica no grupo controle. Por outro lado, LEBLANC et al. (2002) não encontraram efeito da vitamina $E$ sobre a incidência de mastite clínica em vacas injetadas com dose única de 3.000 UI uma semana antes do parto.

Alguns trabalhos foram feitos no Brasil com objetivo semelhante. ZANETTI et al. (1998) observaram que a suplementação oral com 5mg de Se no último mês de gestação aumentou significativamente o nível sérico do mineral nas vacas leiteiras, reduzindo a incidência de mastite subclínica diagnosticada por intermédio do teste CMT. Da mesma maneira, PASCHOAL et al. (2003) concluíram que a suplementação diária com 5mg de selênio e 1.000 UI de vitamina $\mathrm{E}$, iniciada 30 dias antes do parto, diminuiu em $38 \%$ e 53\%, respectivamente, a incidência de mastite clínica nas primeiras 12 semanas de lactação. Os mesmos autores encontraram ainda efeito positivo do selênio $(\mathrm{P}<0,05)$ sobre a contagem de células somáticas, porém não encontraram efeito da vitamina E sobre esta variável (PASCHOAL et al., 2003a). Segundo COSTA et al. (1997), não houve diferença significativa entre o tratamento com Se (0,1 $\left.\mathrm{mg} \mathrm{kg}^{-1} \mathrm{MS}\right)$ e o grupo controle (sem suplementação) quanto à incidência de mastite clínica, diagnosticada por meio do teste da caneca de fundo escuro. Da mesma maneira, MALBE at al. (2003) não encontraram efeito positivo do selênio sobre a incidência de mastite clínica quando suplementaram animais com 0,2ppm Se dia ${ }^{-1}$.

A deficiência de selênio foi constatada em várias regiões do Estado de São Paulo por meio do levantamento dos níveis de Se nas forragens e nos concentrados (LUCCI et al., 1984; GIL et al., 2004), assim como no sangue de vacas leiteiras (ZANETTI et al., 1984; GIL et al., 2004). Os volumosos conservados apresentam baixas concentrações de vitamina E (THAFVELIN \& OKSANEN, 1966) e são amplamente utilizados na alimentação de rebanhos leiteiros. Sabese que durante o período pré-parto o consumo de matéria seca diminui, diminuindo, também, o consumo de vitamina E e de selênio (MILLER et al.,1995).

O objetivo deste trabalho foi estudar o efeito da suplementação de selênio e de vitamina E no préparto sobre a contagem de células somáticas no leite de vacas da raça Holandesa.

\section{MATERIAL E MÉTODOS}

O experimento foi conduzido no município de Descalvado, SP. Oitenta vacas da raça Holandesa de segunda à quinta lactação foram pré-selecionadas durante o período seco, de acordo com a data prevista de parição, entre 02/02/2001 a 23/03/2001. Todos os animais selecionados foram tratados com Rilexine ${ }^{\circledR}$, antibiótico intramamário à base de cefalexina e neomicina, específico para vacas secas, no momento da secagem.

As unidades experimentais foram distribuídas aleatoriamente em quatro tratamentos: 2,5mg de selênio na forma de selenito de sódio, 1.000 UI de vitamina E na forma de acetato de alfa tocoferol, 2,5mg Se + 1.000 UI de vit.E e o controle.

A suplementação foi efetuada com selenito de sódio (P.A. MERCK) diluído em fubá de milho, de modo que cada kg do suplemento continha 500mg de selênio. $\mathrm{O}$ acetato de alfa tocoferol (BASF - Lutavit E 50 \%) também foi diluído em fubá de milho e a dose diária individual dos dois elementos foi pesada e

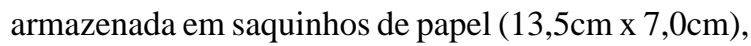
os quais foram colocados diariamente dentro da boca de cada animal. A suplementação iniciou-se 30 dias 
antes da provável data de parição, prolongando-se até a data do parto.

As vacas secas receberam silagem de milho (22kg na matéria natural vaca-1 $\mathrm{dia}^{-1}$ ), silagem de capim napier (5kg na matéria natural vaca ${ }^{-1} \mathrm{dia}^{-1}$ ) e concentrado formulado e misturado na própria fazenda ( $4 \mathrm{~kg}$ na matéria natural vaca ${ }^{-1} \mathrm{dia}^{-1}$ ). Todos os ingredientes foram pesados em um vagão misturador $\mathrm{e}$ fornecidos aos animais pela manhã.

Amostras do volumoso e do concentrado fornecidas às vacas secas foram colhidas quinzenalmente, diretamente do cocho, secadas em estufa a $65^{\circ} \mathrm{C}$, moídas e reservadas para posterior análise. Vinte por cento de cada amostra foram selecionados para a formação de um "pool” o qual foi submetido às análises de matéria seca (MS), de proteína bruta (PB), de extrato etéreo (EE), de matéria mineral (MM), de cálcio ( $\mathrm{Ca})$, de fósforo $(\mathrm{P})$, de acordo com AOAC (1990), fibra em detergente neutro (FDN) de acordo com GOERING \& VAN SOEST (1970) e selênio (OLSON et al., 1975).

Foram realizadas quatro colheitas de sangue de cada vaca para análise do selênio (antes da suplementação, no dia do parto e aos 30 e 60 dias após o parto). Estas amostras foram colhidas da veia mamária em tubos com vácuo, transportadas ao laboratório e centrifugadas por quatro minutos. O soro foi pipetado, acondicionado em eppendorfs de plástico e congelado a $-20^{\circ} \mathrm{C}$. As análises laboratoriais para determinação do selênio foram realizadas no laboratório de minerais da Faculdade de Zootecnia e Engenharia de Alimentos da USP, após a digestão úmida com ácido perclórico $70 \%$ e posterior leitura fluorimétrica, seguindo-se a sensibilização por diamino-naftaleno (OLSON et al., 1975).

As colheitas de leite para levantamento da CCS foram realizadas semanalmente, logo após o período colostral (total de 12 semanas de coleta), durante a ordenha da tarde. Os tubos plásticos, com capacidade de $60 \mathrm{~mL}$ cada, contendo duas pastilhas do conservante dicromato de potássio, foram utilizados para colheita do leite. As amostras foram previamente identificadas, acondicionadas em caixas especiais para transporte e levadas o mais rapidamente possível ao laboratório. A CCS foi realizada por citometria de fluxo (BENTLEY ${ }^{\circledR}$ 300).

O delineamento utilizado foi em blocos para controlar o efeito da ordem de parição dos animais e a contagem inicial de células somáticas foi usada como covariável.

Os níveis de selênio no soro foram comparados em cada tempo de colheita utilizando-se PROC GLM do SAS (1982).

Por não seguirem uma distribuição normal, os valores de contagem de células somáticas (CCS) foram transformados em loge, e, desta forma, reportados. Os dados foram analisados usando-se PROC MIXED do SAS (1982).

\section{RESULTADOS E DISCUSSÃO}

O teor médio do selênio na dieta basal durante o período experimental foi de $0,47 \mathrm{mg} \mathrm{kg}^{-1} \mathrm{MS}$ $(0,47 \mathrm{ppm})$, valor superior ao que foi encontrado nas fazendas do Estado de São Paulo na década de oitenta (LUCCI et al., 1984) e no Estado de Ohio, EUA (WEISS et al., 1990). Atualmente, estão sendo utilizados níveis superiores de selênio, sendo o sal mineral a principal via de fornecimento. Os animais deste experimento, suplementados com 2,5mg de selênio dia ${ }^{-1}$, passaram a consumir 8,1mg de selênio diário ou 0,8ppm, valores similares aos testados por MAUS et al. (1980); WEISS et al. (1990).

Os níveis séricos do selênio no período precedente à suplementação, no parto e aos 30 e 60 dias após o parto estão apresentados na tabela 1. Pelos resultados, observou-se que, antes do início dos tratamentos, os níveis séricos do selênio foram semelhantes $\left(0,057 ; 0,056\right.$ e $0,054 \mu \mathrm{mL}^{-1}$ para os tratamentos controle, selênio e selênio+vit.E, respectivamente), valores superiores àqueles encontrados por ZANETTI et al. (1984), fato explicado pela maior concentração de selênio encontrada na dieta basal. Estes níveis denotam insuficiência do mineral

Tabela 1 - Níveis de selênio $(\mu \mathrm{g} / \mathrm{ml})$ no soro de vacas holandesas nos períodos: antes do parto, no parto, 30 e 60 dias pós-parto.

\begin{tabular}{|c|c|c|c|c|}
\hline Tratamento & Antes do parto & Parto & 30 dias pós-parto & 60dias pós-parto \\
\hline Controle & $0,057^{\mathrm{a}}$ & $0,069^{\mathrm{b}}$ & $0,079^{\mathrm{a}}$ & $0,085^{\mathrm{a}}$ \\
\hline Selênio & $0,056^{\mathrm{a}}$ & $0,082^{\mathrm{a}}$ & $0,088^{\mathrm{a}}$ & $0,088^{\mathrm{a}}$ \\
\hline Se+vitE & $0,054^{\mathrm{a}}$ & $0,085^{\mathrm{a}}$ & $0,091^{\mathrm{a}}$ & $0,085^{\mathrm{a}}$ \\
\hline $\mathrm{EPM}^{(1)}$ & 0,0026 & 0,0021 & 0,0034 & 0,0023 \\
\hline
\end{tabular}

Médias seguidas de letras diferentes na coluna diferem pelo teste de Tukey $(\mathrm{P}<0,05)$.

${ }^{(1)}$ Erro padrão da média. 
para haver aumento na resistência da glândula mamária, cujo valor recomendado situa-se na faixa de $0,080 \mu \mathrm{mL}^{-1}$ (WEISS et al., 1990). No momento do parto, ou seja, um mês após a suplementação, vacas que receberam selênio ou selênio associado à vitamina $\mathrm{E}$ apresentaram níveis séricos superiores $(\mathrm{P}<0,05)$ ao grupo controle $\left(0,082 ; 0,085 ; 0,069 \mu \mathrm{mL}^{-1}\right.$, respectivamente), alcançando os níveis recomendados, o que mostrou ser suficiente o período de suplementação utilizado. Estes resultados são semelhantes aos obtidos por ZANETTI et al. (1998), os quais encontraram aumento significativo nos níveis séricos do selênio após 30 dias de suplementação com o mineral. De acordo com MAUS et al. (1980), a suplementação com $6 \mathrm{mg}$ selênio dia ${ }^{-1}$ conseguiu manter a concentração sérica do selênio em níveis adequados e semelhantes aos obtidos neste trabalho.

Trinta dias após o parto, os níveis séricos do selênio igualaram-se. Tal fato pode ser explicado pelo término da suplementação e pela alteração da dieta de todos os animais, pois, estando em produção, todos os grupos passaram a receber maior quantidade de concentrado por dia, e, conseqüentemente, maior quantidade de selênio.

Os resultados relativos à contagem de células somáticas (CCS) nas doze primeiras semanas de lactação estão apresentados na tabela 2. Não foi encontrado efeito do selênio $(\mathrm{P}=0,88)$ e da vitamina $\mathrm{E}$ $(\mathrm{P}=0,56)$ sobre a CCS nas primeiras doze semanas de lactação e não houve interação significativa entre os dois elementos $(\mathrm{P}=0,46)$, quando os dados foram analisados na presença e/ou na ausência de cada um dos elementos. A ordem de parição também não teve influência sobre esta variável $(\mathrm{P}>0,10)$.

Tabela 2 - Contagem de células somáticas $\left(\log _{e}\right)$ no leite de vacas suplementadas com selênio (Se) e vitamina E (vit. E) até a décima segunda semana de lactação.

\begin{tabular}{lc}
\hline & Média das 12 semanas \\
\hline Controle & 6,43 \\
Se & 5,93 \\
vit.E & 6,69 \\
Se + vit. E & 6,31 \\
Sem Se & 6,39 \\
Com Se & 6,26 \\
Sem vit.E & 6,50 \\
Com vit.E & 6,15 \\
& \\
Se & Probabilidade \\
vit.E & 0,88 \\
Interação & 0,56 \\
\hline
\end{tabular}

Em trabalho publicado recentemente no Brasil, PASCHOAL et al. (2003) constataram que a suplementação com nível de selênio superior ao utilizado neste trabalho ( $\left.5 \mathrm{mg} \mathrm{Se}_{\mathrm{dia}}{ }^{-1}\right)$ diminuiu a CCS nas oito primeiras semanas de lactação; os autores não encontraram efeito da vitamina E sobre esta variável, concordando com os resultados obtidos no presente estudo. COSTA et al. (1997) não obtiveram resultados positivos com a suplementação de selênio quando utilizaram baixo teor suplementar.

Do mesmo modo, a suplementação com vit. E em níveis crescentes aumentou a concentração de alfa tocoferol no sangue (mais significativo em vacas secas) e diminuiu a incidência de mastite clínica (WEISS et al., 1990).

A suplementação com níveis crescentes de vit.E realizada por WEISS et al. (1990) aumentou a concentração de alfa tocoferoal no sangue, porém os autores não encontraram correlação entre níveis de vitamina E no sangue e a CCS $(\mathrm{P}<0,25)$. Do mesmo modo, ZANETTI et al. (1998) não encontraram diminuição da mastite subclínica diagnosticada por meio do teste CMT em vacas recebendo vitamina E, porém encontraram efeito positivo do selênio após suplementação com $5 \mathrm{mg}$ dia $^{-1}$. VALLE (2000) não encontrou efeito da vitamina $E$ sobre a incidência de mastite subclínica, concordando com os resultados apresentados. WEISS et al. (1997) encontraram resultados benéficos da vitamina $\mathrm{E}$ sobre a incidência de mastite subclínica quando utilizaram níveis mais altos de suplementação (2000 UI vitE dia $^{-1}$ ).

\section{CONCLUSÕES}

A suplementação com selênio e vitamina E realizada no pré-parto não afetou a contagem de células somáticas do leite possivelmente devido aos baixos níveis utilizados. Os resultados desta pesquisa evidenciam a necessidade de realização de outros estudos relacionados aos níveis suplementares e formas de administração para melhor avaliar os efeitos da suplementação de minerais e de vitaminas na prevenção e no controle da mastite.

\section{REFERÊNCIAS}

AOAC. Official Methods of Analysis. 12.ed. Washington, DC, 1990. 1094p.

COMBS, G.F., Jr.; COMBS, S.B. The role of selenium in nutrition. London: Academic, 1986. 180p.

COSTA, E.O. et al. Influência da suplementação de selênio na incidência de mastite. Revista Brasileira de Medicina Veterinária, v.19, p.169-172, 1997. 
COSTA, E.O. et al. Índices de mastite bovina clínica e subclínica nos Estados de São Paulo e Minas Gerais. Revista Brasileira de Medicina Veterinária, v.17, p.215-217, 1995.

COSTA, E.O. et al. Mastite subclínica: prejuízos causados e os custos de prevenção em propriedades leiteiras. Revista Napgama, v.2, p.16-20, 1999.

GIL, S. et al. Medição dos níveis de selênio no plasma bovino, solo e forragem por meio de análises de ativação neutrônica. Arquivo Brasileiro de Medicina Veterinária e Zootecnia, v.56, p.264-266, 2004.

GOERING, G.K.; VAN SOEST, P.J. Forage fiber analysis (apparatus, reagents, procedures and some applications), Washington DC.: USDA, 1970. 379p. (USDA Agriculture Handbook).

LANGONI, H. Tendências de modernização do setor lácteo: monitoramento da qualidade do leite pela contagem de células somáticas. Revista Educação Continuada CRMV-SP, v.3, p.57-64, 2000.

LEBLANC, S.J. et al. The effect of prepartum injection of vitamin $E$ on health in transition dairy cows. Journal of Dairy Science, v.85, p.1416-1426, 2002.

LUCCI, C.S. et al. Selênio em bovinos leiteiros do estado de São Paulo. I. Níveis de Selênio em soros sangüíneos. Revista Faculdade de Medicina Veterinária e Zootecnia da Universidade de São Paulo, v.21, p.65-70, 1984.

MALBE, M. et al. Effects of oral selenium supplementation on mastitis markers and pathogens in Estonian cows. Veterinary Theriogenology, v.4, n.2, p.145-154, 2003.

MAUS, R.F. et al. Relationship of diet selenium to selenium in plasma and milk from dairy cows. Journal of Dairy Science, v.63, p.533-537, 1980.

MILLER, G.Y. et al. Factors affecting serum selenium and vitamin E concentrations in dairy cows. Journal of American Veterinary Medical Association, v.206, n.09, p.1369-1373, 1995.

OLSON, O.E. et al. Modification of the official Fluorimetric method for selenium in plants. Journal of Association of Official Analytical Chemists, v.58, p.117-121, 1975.

PAES, P.R.O. et al. Efeitos da administração de vitamina E na infecção mamária e na contagem de células somáticas de cabras primíparas desafiadas experimentalmente com Staphylococcus aureus. Arquivo Brasileiro de Medicina Veterinária e Zootecnia, v.55, p.15-20, 2003.

PASCHOAL, J.J. et al. Efeito da suplementação de selênio e vitamina E sobre a incidência de mastite clínica em vacas da raça holandesa. Arquivo Brasileiro de Medicina Veterinária e Zootecnia, v.55, p.249-255, 2003.

PASCHOAL, J.J. et al. Efeito da suplementação de selênio e vitamina E sobre a contagem de células somáticas do leite de vacas da raça holandesa. Revista Brasileira de Zootecnia, v.32, p.2032-2039, 2003a.

SAS User's Guide Version 6.4.Ed. Cary: SAS Institute, 1982. 1022p.

SMITH, K.L. et al. Effect of vitamin E and Selenium supplementation on incidence of clinical mastitis and duration of clinical symptoms. Journal of Dairy Science, v.67, p.1293-1300, 1984.

THAFVELIN, B.; OKSANEN, H.E. Vitamin E and linolenic acid content of hays as related to different drying conditions. Journal of Dairy Science, v.49, p.282-286, 1966.

VALLE, C.R. Influência da suplementação de vitamina $\mathbf{E}$ nos períodos pré e pós parto na ocorrência de mastite clínica. 2000. 76f. Dissertação (Mestrado em Zootecnia) Faculdade de Zootecnia e Engenharia de Alimentos, Universidade de São Paulo.

WEISS, W.P. et al. Relationship among selenium, vitamin E and mammary gland health in commercial dairy herds. Journal of Dairy Science, v.73, p.381-390, 1990.

WEISS, W.P. et al. Effect of vitamin E supplementation in diets with a low concentration of Selenium on mammary gland health of dairy cows. Journal of Dairy Science, v.80, p.17281737, 1997.

ZANETTI, M.A. et al. Selênio em bovinos leiteiros do Estado de São Paulo. V. Suplementação de Selênio para vacas em fase final de gestação. Revista da Faculdade de Medicina Veterinária e Zootecnia da Universidade de São Paulo, v.21, p.141-145, 1984.

ZANETTI, M.A. et al. Efeito da suplementação de Selênio e Vitamina E em bovinos leiteiros. Revista Brasileira de Zootecnia, v.27, p.405-408, 1998. 